\title{
Palmar flexion creases and finger linkage groups in New World monkeys - functional and evolutionary palmistry
}

\author{
Mellin Novikova ${ }^{1}$, and Alexander Kuznetsov ${ }^{2}$ \\ 1 Faculty of Biology, Lomonosov Moscow State University, \\ 1-12 Leninskie Gory, Moscow, 119234, Russian Federation; \\ 2 Borissiak Paleontological Institute, Russian Academy of Sciences, \\ Profsoyuznaya st. 123, Moscow, 117647, Russian Federation. \\ Address correspondence and requests for materials to Alexander Kuznetsov, \\ sasakuzn@mail.ru
}

\begin{abstract}
Manipulatory abilities and activities of primate hands are crucially important for humanity's understanding of our own species, and they have been very well studied in diverse aspects. However, there remains a surprising ignorance as to the variety of flexion creases on primate palms and their functional and evolutionary significance. Here we present the first extensive attempt to fill this gap. Major attention is paid to New World monkeys known for the diversity of their grasping adaptations, which exceeds that of prosimians, Old World monkeys and apes together. The presented analysis is based on the assumption that the palmar flexion creases border groups of fingers which are used together which we suggest naming "finger linkage groups". We show that this assumption is in agreement with what is known about hand usage in locomotion and manipulation by different primates. Here we show that the Life Line bordering the thumb is present in all primates manifesting the basic ability of thumb opposition, which can be enhanced (like in humans or capuchins) or reduced (like in marmosets or spider monkeys). Longitudinal creases (Fate Line) seem to have appeared early in evolution, as they are present in lemurs, marmosets, and some Old World monkeys; typically, two longitudinal creases are present (humans show one as a variation). The longitudinal creases were replaced in simian evolution by transversal ones, of which the most common is the Simian Line bordering fingers II-V and facilitating a power grip by these four fingers against the palm. This four-finger crease is the only type of transversal creases known in Old World monkeys and apes (the last have two such creases). In marmosets the transversal crease borders all five fingers, while in schizodactylous New World Monkeys it borders only the three last fingers. Apart from them, such a three-finger crease, known as the Heart Line, is found in humans only. However, its origin is different. In human evolution, it was most likely produced by a breakage of the ancestral Simian Line into two, the second half being represented by the unique human Head Line. This breakage dislinked the index finger from the power grip, allowing for pointing gestures and individual usage of this finger.
\end{abstract}

Keywords: palmar flexion creases, finger linkage groups, Platyrrhini, functional morphology

\section{Introduction}

Kuznetsov. This is an open-access article distributed under the terms of the License Agreement with Saint Petersburg State University, which permits to the authors an unrestricted distribution and self-archiving free of charge.

Funding: This work was supported by the Russian Foundation for Basic Research (grants 15-04-05049 and 17-04-00954).

In primates, just as in humans, the hairless surface of the palm is covered by flexion creases and papillary (tactile) patterns. Anthropologists, surgeons, criminalists and other specialists who use dermatoglyphics in their work are usually concerned only by the papillary patterns on palms and fingertips. Flexion creases, for the most part, are only the focus of chiromancy. So far the only point of interest for surgeons is the association of creases with skeletal elements. For example, 
flexion creases can mark the joints and places where the underlying palm fascia is connected to the skin. Those are quite crucial in case of surgery (Chauhan et al., 2011). Main creases can also correspond to muscles, for example the Life Line indicates the edge of $m$. adductor pollicis (Tegako, 2008). In dermatoglyphics, flexion creases are used as reference points in the description of papillary patterns and to pinpoint important elements, such as triradii (a connection point of three papillary line groups) (Zvyagintseva, 1940; Midlo and Cummins, 1942; Danilova, 1979).

Prehension abilities of the hand are based on its internal morphology, in particular the finger muscles, the structure of which can cause mechanical linkage of certain fingers (Novikova and Panyutina, 2017). On the other hand, external palm morphology - in particular, overall proportions, palm pads, papillary patterns, nails/claws and most of all flexion creases - can serve as a mirror for these mechanical properties. Palmar flexion creases are usually located between the palm pads, bordering or separating them. Palm pads can be flat or bulging, depending on the substrate relief habitual to an animal. Formation of creases may be considered a subsequent, more advanced stage of the evolution of prehension, which is indirectly suggested by their late embryonic development relative to the pads (Swindler et al., 1968; Bali, 1994; Kimura et al., 2002). As the pads precede the creases both in evolution and in embryogenesis, topography of the former may be reasonably regarded as the basis for topography of the latter (Popich and Smith, 1970; Jeanty et al., 2011). We will concentrate on the flexion creases.

It is convenient to start with human flexion creases, because (1) flexion creases were originally described for humans, (2) the human palm has the most complete set of creases, and (3) they are available for everyone to observe. Brief descriptions and pictograms of the human flexion creases that are most important for further consideration of the primate palm and grip are presented in Table 1 and Figure 1. An x-ray from Chauhan (2011) is used as a background to highlight associations between the skeleton and the flexion creases. Normally, there are three primary and several secondary palmar flexion creases in humans. The former are always present (except for rare abnormalities considered below in detail), while the number and pattern of the secondary creases is variable; as such, they are also called irregular, while the primary creases are referred to as regular. The primary palmar flexion creases are the first to form in embryogenesis (Bali, 1994) and stay the same throughout life. Therefore, they can be observed on both adult and juvenile specimens. Primary flexion creases can be recognized on the palm by their prominence (length, width, depth). Due to size differences, the primary (regular) and secondary (irregular) creases can be well distinguished without knowing their morphogenesis or variation, and are often called simply major and minor creases (Park et al., 2010).

Embryonic development of the palm relief starts with the appearance of palm pads, which can be found in a human fetus as mesenchymal swellings beginning in the seventh week of gestation (Gyenis and Hera, 1971). The primary flexion creases are formed later and can be found starting from the second or third month of gestation (Wurth, 1937). Due to different evaluation methods, there is no consensus among different researches on the exact timing of crease formation (Popich and Smith, 1970; Bali, 1994; Lacroix et al., 1984; Kimura and Kitagawa, 1986; Stevens et al., 1988). However, the order of their formation is accepted unequivocally - the Life Line is formed first (week 8), followed by the Heart Line (week 11) and Head Line (week 13) (Kimura, 1991). Note that human fetuses begin spontaneous hand movements no earlier than the 12th week of gestation (Humphrey, 1964). Hence, the primary flexion creases are acquired not as a consequence of the flexion movements of the palm but are preformed relative to their function (Wurth, 1937; Kimura et al., 2002).

The attractive idea of functional determination of creases by movements (Popich and Smith, 1970; Jeanty et al., 2011) is still applicable to the secondary creases that develop later. The Fate Line only appears during the fifth month of fetal development (Asano, 1985; Bali, 1994), and all other secondary creases are formed starting from the seventh month or after birth, due to flexion movements when skin loses its elasticity; and these secondary creases can change with age (Tegako, 2008). They are highly variable in position and number, some of them occurring more frequently than others (Martin, 1928). Viliamovskaya (1955) described eleven irregular creases in humans, with bilateral, gender, and geographic variations.

It is necessary to give special consideration to the formation of the Simian Line, a well-known human abnormality. If it forms, this happens late in embryogenesis. The earliest it has been found was at 15 weeks of gestation (Sherer and Abramowicz, 1991). It was first described by Langdon-Down and was later named "Mongolian" or "Orangoid" by Crookshank (Bali, 1994). Further research showed that formation of the Simian Line in humans usually correlates with several chromosomal anomalies such as trisomy of chromosome 21 (Down's Syndrome) or some pathological changes in chromosomes 13, 18, or 21 (Aziz and Dunlap, 1986). The presence of the Simian Line is not the sole and mandatory expression of those chromosomal anomalies, so a complex of more than 30 dermatoglyphic features is used in their diagnostics (Tegako, 2008). Although more rarely than in cases of chromosomal anomalies, the Simian Line can also occur in healthy individuals. In the aforementioned 


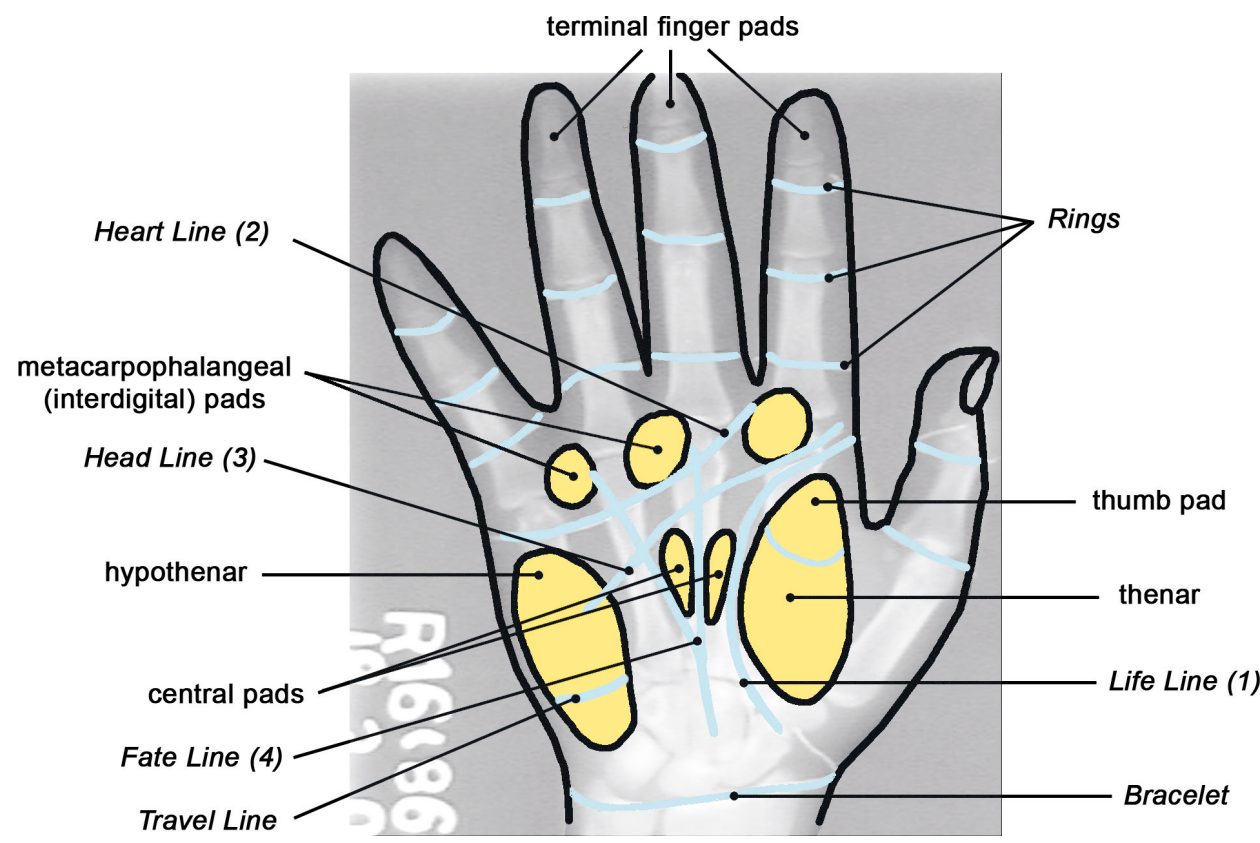

Fig. 1. Diagram of palm pads and flexion creases plotted on radiograph of hand skeleton. Numbers in parentheses represent the order in which the most important creases appear in embryogenesis. Modified after Chauhan et al. (2011)

Table 1. Summary of human palmar flexion creases

Primary creases

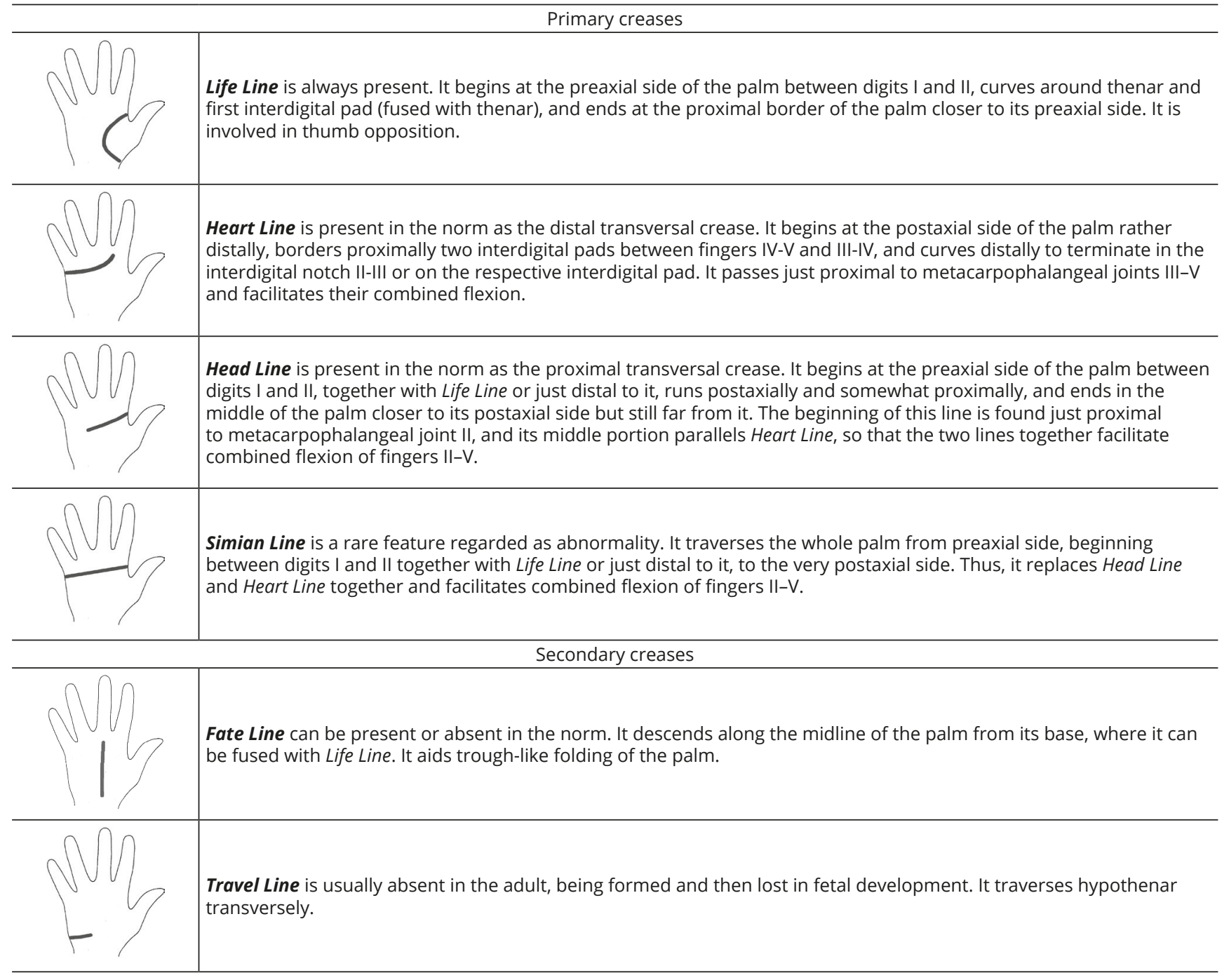



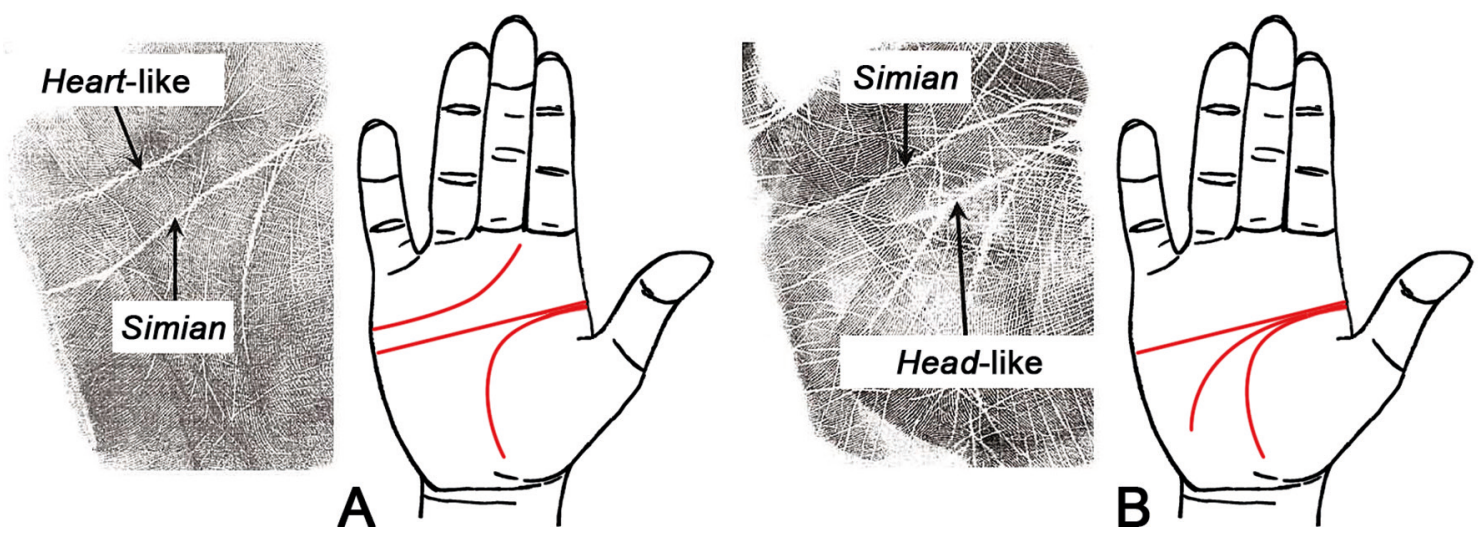

Fig. 2. Life Line (not labeled), Simian Line and accessory creases in Sydney (A) and Suwon (B) variations of human palm relief. Modified after Sharma and Sharma (2011)

Table 2. Material. Abbreviations: IPEE RAS - Severtsov Institute of Ecology and Evolution, Russian Academy of Sciences; Vert. Zool. MSU - Department of Vertebrate Zoology, Faculty of Biology, Lomonosov Moscow State University; ZIN RAS - Zoological Institute, Russian Academy of Sciences; ZMMU - Zoological Museum, Lomonosov Moscow State University. All the lifetime photos from the Internet were available for downloading on November 24, 2017 and corresponding links are provided in the Used internet resourses section in the end of the article (pp. 199-201)

\begin{tabular}{|c|c|c|c|c|}
\hline Species & Type & Number & Age & Source \\
\hline \multicolumn{5}{|l|}{ SCANDENTIA } \\
\hline Tupaia belangeri & Alcohol specimen & 1 & $\mathrm{ad}$ & ZMMU \\
\hline \multicolumn{5}{|l|}{ PRIMATES } \\
\hline \multicolumn{5}{|l|}{ STREPSIRRHINI } \\
\hline \multicolumn{5}{|l|}{ Lemuridae } \\
\hline Lemur catta & Lifetime photo & 4 & $\mathrm{ad}$ & Internet \\
\hline \multicolumn{5}{|l|}{ Loridae } \\
\hline Nycticebus sp. & Lifetime photo & 1 & $\mathrm{ad}$ & Internet \\
\hline Perodicticus potto & Lifetime photo & 1 & $\mathrm{ad}$ & Internet \\
\hline \multicolumn{5}{|l|}{ Galagonidae } \\
\hline Galago senegalensis & Frozen specimen & 1 & $\mathrm{ad}$ & IPEE RAS \\
\hline \multicolumn{5}{|l|}{ PLATYRRHINI } \\
\hline \multicolumn{5}{|l|}{ Cebidae } \\
\hline \multirow[t]{3}{*}{ Callithrix jacchus } & Lifetime photo & 4 & $\mathrm{ad}$ & Internet \\
\hline & Alcohol specimen & 1 & $\mathrm{ad}$ & ZIN RAS \\
\hline & Frozen specimen & 1 & $\mathrm{ad}$ & IPEE RAS \\
\hline \multirow[t]{2}{*}{ Callithrix penicillata } & Alcohol specimen & 1 & $\mathrm{ad}$ & Vert. Zool. MSU \\
\hline & Lifetime photo & 1 & $\mathrm{ad}$ & Internet \\
\hline \multirow[t]{3}{*}{ Cebuella pygmaea } & Lifetime photo & 4 & $\mathrm{ad}$ & Internet \\
\hline & Alcohol specimen & 1 & $\mathrm{ad}$ & IPEE RAS \\
\hline & Frozen specimen & 2 & $\mathrm{ad}$ & IPEE RAS \\
\hline Saguinus fuscicollis & Frozen specimen & 1 & $\mathrm{ad}$ & IPEE RAS \\
\hline Saguinus oedipus & Lifetime photo & 2 & $\mathrm{ad}$ & Internet \\
\hline Saguinus geoffroyi & Frozen specimen & 2 & ad, newborn & IPEE RAS \\
\hline Saguinus imperator & Lifetime photo & 1 & $\mathrm{ad}$ & Internet \\
\hline Saguinus midas & Frozen specimen & 3 & 2 ad, 1 juv & IPEE RAS \\
\hline \multirow[t]{2}{*}{ Leontopithecus rosalia } & Alcohol specimen & 1 & $\mathrm{ad}$ & ZIN RAS \\
\hline & Lifetime photo & 1 & $\mathrm{ad}$ & Internet \\
\hline \multirow[t]{2}{*}{ Cebus capucinus } & Lifetime photo & 1 & $\mathrm{ad}$ & Internet \\
\hline & Alcohol specimen & 1 & $\mathrm{ad}$ & ZIN RAS \\
\hline Sapajus apella & Alcohol specimen & 1 & $\mathrm{ad}$ & Vert. Zool. MSU \\
\hline \multirow[t]{3}{*}{ Saimiri sciureus } & Lifetime photo & 4 & $\mathrm{ad}$ & Internet \\
\hline & Alcohol specimen & 1 & $\mathrm{ad}$ & Vert. Zool. MSU \\
\hline & Frozen specimen & 2 & ad & IPEE RAS \\
\hline \multicolumn{5}{|l|}{ Pitheciidae } \\
\hline \multirow[t]{2}{*}{ Cacajao calvus } & Lifetime photo & 1 & $\mathrm{ad}$ & Internet \\
\hline & Alcohol specimen & 1 & newborn & ZMMU \\
\hline
\end{tabular}




\begin{tabular}{|c|c|c|c|c|}
\hline \multicolumn{5}{|l|}{ Atelidae } \\
\hline Alouatta seniculus & Alcohol specimen & 1 & newborn & ZIN RAS \\
\hline Alouatta caraya & Lifetime photo & 1 & ad & Internet \\
\hline Ateles belzebuth & Lifetime photo & 2 & $\mathrm{ad}$ & $\begin{array}{l}\text { By author, } \\
\text { Internet }\end{array}$ \\
\hline Ateles geoffroyi & Lifetime photo & 1 & $\mathrm{ad}$ & Internet \\
\hline Ateles sp. & Lifetime photo & 1 & $\mathrm{ad}$ & Internet \\
\hline Brachyteles arachnoides & Lifetime photo & 1 & $\mathrm{ad}$ & Internet \\
\hline Lagothrix lagotricha & Lifetime photo & 1 & $\mathrm{ad}$ & Internet \\
\hline \multicolumn{5}{|l|}{ CATARRHINI } \\
\hline \multicolumn{5}{|l|}{ Cercopithecidae } \\
\hline \multirow[t]{2}{*}{ Chlorocebus sabaeus } & Alcohol specimen & 2 & juv & ZMMU \\
\hline & Lifetime photo & 1 & ad & Internet \\
\hline Cercopithecus neglectus & Lifetime photo & 1 & $\mathrm{ad}$ & \begin{tabular}{|l|} 
Internet \\
\end{tabular} \\
\hline Macaca mulatta & Lifetime photo & 1 & $\mathrm{ad}$ & Internet \\
\hline Macaca fuscata & Lifetime photo & 2 & ad & Internet \\
\hline Macaca arctoides & Frozen specimen & 1 & juv & IPEE RAS \\
\hline Colobus sp. & Lifetime photo & 2 & ad & Internet \\
\hline \multicolumn{5}{|l|}{ Hylobatidae } \\
\hline Hylobates lar & Lifetime photo & 2 & $\mathrm{ad}$ & Internet \\
\hline Hylobates pileatus & Lifetime photo & 1 & $\mathrm{ad}$ & Internet \\
\hline \multicolumn{5}{|l|}{ Hominidae } \\
\hline Pan troglodytes & Lifetime photo & 1 & $\mathrm{ad}$ & Internet \\
\hline Pan paniscus & Lifetime photo & 1 & $\mathrm{ad}$ & \begin{tabular}{|l|} 
Internet \\
\end{tabular} \\
\hline Pan sp. & Lifetime photo & 2 & $\mathrm{ad}$ & \begin{tabular}{|l|} 
Internet \\
\end{tabular} \\
\hline Gorilla sp. & Lifetime photo & 3 & $\mathrm{ad}$ & Internet \\
\hline \multirow[t]{2}{*}{ Pongo pygmaeus } & Lifetime photo & 3 & $\mathrm{ad}$ & \begin{tabular}{|l|} 
Internet \\
\end{tabular} \\
\hline & Lifetime photo & 1 & juv & Internet \\
\hline
\end{tabular}

case, when it was detected in an embryo at 15 weeks gestation, a normal karyotype was observed (Sherer and Abramowicz, 1991). Jeanty et al. (2011) found a Simian Line in $45 \%$ of people suffering trisomy of chromosome 21 and in $5 \%$ of the healthy population, in which $4 \%$ of individuals bore it unilaterally, and $1 \%$ - bilaterally. It was found more frequently on right than on left hands, and in men than in women (Bali, 1994). The Simian Line is less frequent (4\%) in Caucasians than in Asians (13\%) (Sharma and Sharma, 2011). It is even more frequent in archaic peoples such as Melanesians (15\%) and African Pygmies (17\%) (Kimura, 1968). The Simian Line looks like a product of fusion of normal Heart and Head Lines. The fact that these three lines never occur together supports this view. However, sometimes abnormal combinations of two lines, passing transversely, are found the so-called "Sydney" and "Suwon" patterns (Fig. 2). In the Sydney pattern, the Simian Line occurs together with a crease which looks like a Heart Line, in the Suwon pattern - with a crease which looks like a Head Line. In both cases those accessory lines would be false if the Simian Line was in fact a fusion of true ones (see Discussion). Also, cases have been described in which different variations were combined in one person: (1) Simian Line on one hand, Suwon pattern on the other, (2) Suwon pattern on one hand, Sydney on the other (Sharma and Sharma, 2011).
The relation of the human Simian Line to palmar flexion creases of simians is still unknown due to the poor knowledge and understanding of the external morphology of primate palms. In this work we attempt to partially fill the gap - first, to describe flexion creases of the primate palm and, second, to figure out their associations with specializations in grasping objects or gripping support. The first task was completed using our original data on palmistric diversity in New World monkeys, known for their diversity of grasping postures, and in some other primates for comparison. For our analysis we have concentrated on the primary flexion creases and the most pronounced secondary creases, which in our opinion can shed light on the evolution of prehension mechanisms. Mainly, we consider genus-level diversity and only infer general tendencies, because data currently available to us regarding individual variability of flexion creases in different primate species are insufficient for a more detailed analysis. The second task covers two levels of functional associations, both of which were studied mainly by analysis of available literature; they are 1) the associations of palmar flexion creases and finger cooperations and 2) the associations of the latter with grasping postures commonly used by the animals under study during locomotion or manipulation.

The idea that flexion creases develop on the palm to facilitate its flexion motions is rather obvious and 
straightforward. Data on human hand anomalies, such as finger fusions, deficiencies, duplications, etc., suggest that finger linkage can be a direct functional cause for crease patterning (Popich and Smith, 1970; Jeanty et al., 2011). However, the normal primary creases develop before onset of spontaneous flexions in human fetuses. Hence, their association with function, if present, is indirect but mediated by natural selection. One can hypothesize that only those creases which border the bases of finger groups habitually flexed together - and thus facilitate appropriate skin folding on the palm - should be most likely supported in the evolutionary scale. In other words, finger linkage should be most associated with grasping postures typical to an animal. We will call cooperating fingers "linkage groups".

\section{Materials and methods}

Neither of the aforementioned research procedures requires ethical permission. Palmar flexion creases were studied by superficial observation of palms or their photos of 46 individuals of New World monkeys, alive, thawed or preserved in alcohol; in addition, primates from other taxa (31 lifetime photos or specimens) and a tree shrew (Tupaia, one specimen) were examined as representatives of out-groups (Table 2). Note that some specimens were newborn or juvenile and could therefore lack some secondary flexion creases or exhibit them in an underdeveloped state, but necessarily exhibit the primary creases, which, by definition, are formed long before birth. Some flexion creases which are absent or secondary (irregular) in humans seem to be primary (regular) in monkeys. Since we have only human embryonic data and do not know in which order flexion creases form in prosimians, monkeys and apes, we consider only lines that are morphologically well pronounced as primary ones. A similar morphological definition of primary (major) vs. secondary (minor) creases has been recently applied to humans (Park et al., 2010).

\section{PALMAR FLEXION CREASES NOMENCLATURE}

Primary flexion creases were classified several times by specialists in different fields; hence, they have synonyms reflecting their topography, functional association with finger flexion or "palmistric idea" (Table 3). Since the latter names are more memorable, we use them here for greater convenience.

To designate two extremities of a flexion crease as the beginning and the end, it is convenient to divert from common morphological landmarks such as preaxial and postaxial edges or the center of the palm, and use the following logic: the crease extremity which is always clearly visible is its beginning, while the opposite one, which can be forked or unclear, is its end.

\section{PREHENSION TYPOLOGY}

The typology of primate grasping postures is well developed. Below is the hierarchical list of key distinctions in this field based mainly on Napier (1956), Bishop (1962), and Fragaszy (2016), with some minor modifications convenient for our purposes and brief explanations.

1. Prehensive pattern - a preparatory posture acquired by hands before gripping and dependent on an animal's ability of neuro-muscular control over hand elements. Gestures may be also regarded as prehensive patterns.

1.1. With only general control of hand posture (initially called "whole-arm control" by Bishop, 1962).

1.2. With fine control of individual finger positions (initially called "fine control of the hand" by Bishop, 1962).

2. Prehensive grip - a posture of a hand holding an object dependent on functional abilities of the former as well as physical properties of the latter.

2.1. Power grip - holding an object between fingers and palm.

2.2. Precision grip - holding an object between fingers only.

2.2.1. Hook grip - holding object between finger tips and bases.

2.2.2. Scissor grip - holding object between finger sides.

2.2.2.1. Schizodatylous grip (side-to-side adduction of fingers II and III).

2.2.2.2. Side-to-side adduction of fingers I and II.

2.2.3. Oppositional grip with the thumb (Fig. 3).

2.2.3.1. Pad(I)-to-pad(II) or to other pads opposition.

2.2.3.2. Pad(I)-to-side(II) opposition; it is intermediate between the padto-pad and scissor grips combining thumb opposition and adduction to the index finger.

2.2.4. Forceps grip; we hypothesize that Leontopithecus rosalia can take an object with its joined three middle fingers on one side and fingers I and $\mathrm{V}$ on the other (see Discussion).

\section{Results}

The data we have collected allow us to identify flexion creases on the palms of non-human primates that in some way or another correspond to those of humans. However, the set of creases which is considered a "nor- 


\section{Pad-to-side}

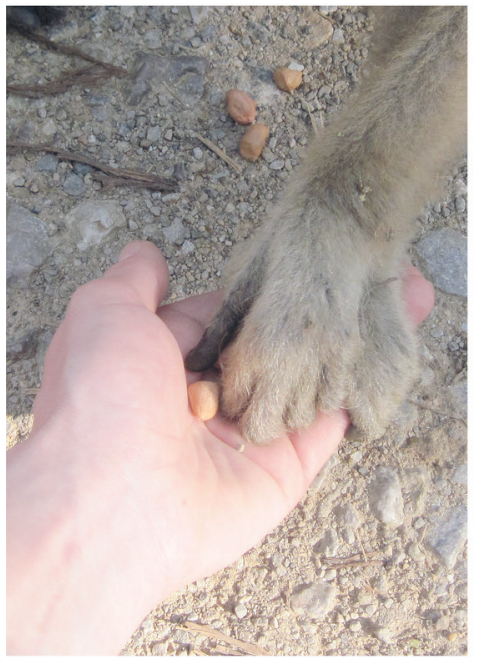

A

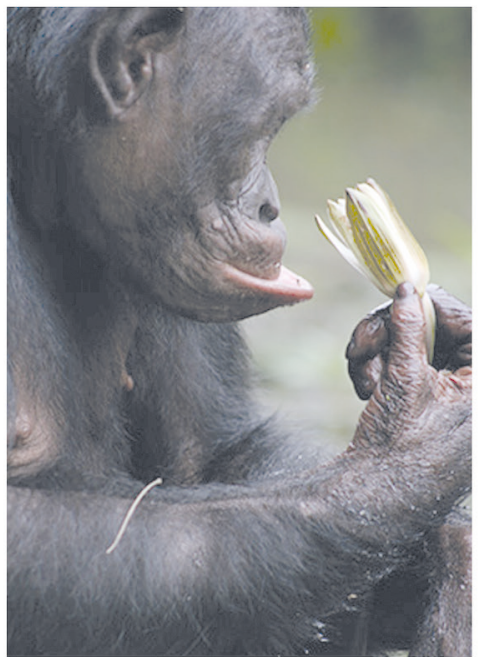

$\mathrm{B}$

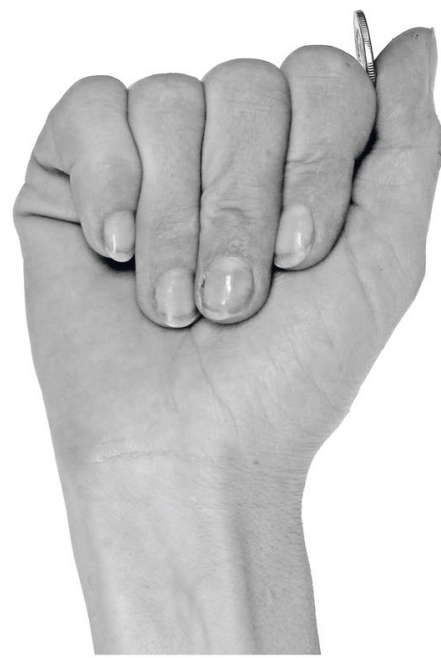

C

\section{Pad-to-pad}

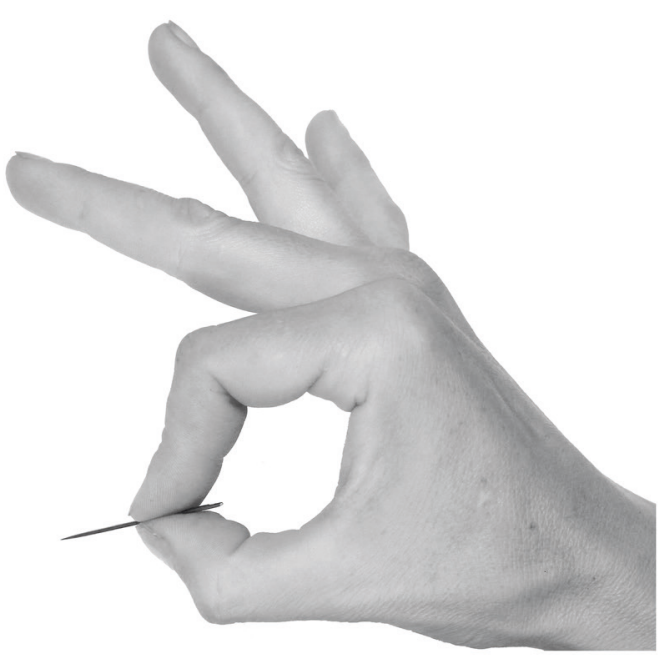

D

Fig. 3. Two types of oppositional grip of small objects by (A) Hylobates, (B) - Pan (photo by Vanessa Woods from http:// www.vanessawoods.net/img/img_bonobo_1.jpg), and (C, D) Homo

Table 3. Synonymy of flexion creases (based on Viliamovskaya, 1955; Danilova, 1979; Park et al., 2015; Kachlik et al., 2015)

\begin{tabular}{|c|c|c|c|}
\hline Palmistric & Topographic & Functional & Medical \\
\hline Bracelets & wrist creases & & plicae flexoriae carpales \\
\hline Travel Line & $\begin{array}{l}\text { hypothenar, or transversal hypothenar } \\
\text { crease }\end{array}$ & & sulcus transversa hypothenaris \\
\hline Life Line & thenar, or radial longitudinal crease & $\begin{array}{l}\text { one-finger, or } \\
\text { thumb crease }\end{array}$ & plica flexoria pollicis \\
\hline Head Line & proximal transversal crease & & plica flexoria transversa proximalis \\
\hline Simian Line & single transversal crease (proximal + distal) & four-finger crease & \\
\hline Heart Line & distal transversal crease & three-finger crease & plica flexoria transversa distalis \\
\hline Fate Line & median, or ulnar longitudinal crease & & sulcus longitudinalis medianus \\
\hline Basal Rings & metacarpophalangeal creases & & plicae flexoriae metacarpo-phalangeales \\
\hline Finger Rings & interphalangeal, or digital creases & & sulci interphalangei proximales et distales primi et secundi \\
\hline
\end{tabular}


Table 4. Combinations of flexion creases normally observed on the palms of certain primates. Double horizontal lines separate Strepsirrhini, Platyrrhini, and Catarrhini. "-" - the crease is always absent in the normal set, "+" - the crease is always present in the normal set, "-I+" - the crease can be absent or present in the normal set but is not regarded as an anomaly. The absence or presence is additionally highlighted by cell coloration. For multiple creases, their usual numbers are represented in parentheses

\begin{tabular}{l|c|c|c|c|c}
\hline & Life Line & Fate Line & Simian Line & Heart Line & Head Line \\
\hline Galago 1 & - & - & - & - & - \\
\hline Lemur & + & $+(2)$ & -2 & - & - \\
\hline Callithrix, Cebuella & + & $+(2)$ & -2 & - & - \\
\hline Leontopithecus & + & $+(1)$ & -2 & - & - \\
\hline Saguinus & + & $+(1)$ & - & - & - \\
\hline Saimiri & + & $+(1-2)$ & $-/+$ & - & - \\
\hline Cebus & + & - & + & - & - \\
\hline Ateles & + & - & + & - & - \\
\hline Alouatta & + & - & - & + & - \\
\hline Cacajao & + & - & - & + & - \\
\hline Lagothrix & + & - & - & + & - \\
\hline \hline Chlorocebus & + & $-/+$ & + & - & - \\
\hline Macaca & + & $-/+$ & + & - & - \\
\hline Hylobates & + & $-/+$ & $+(1-2)$ & - & - \\
\hline Pongo & + & $-/+$ & $+(2)$ & - & - \\
\hline Gorilla & + & $-/+$ & $+(2)$ & $?^{3}$ & - \\
\hline Pan & + & $-/+$ & $+(2)$ & $?^{3}$ & + \\
\hline Homo & + & $-/+$ & $-/+$ & + & - \\
\hline
\end{tabular}

${ }^{1}$ In Galago, like in tupaias, the flexion creases are not properly developed, because the palm surface is not flattened; the pads on the palm are separated by fissures representing predecessors of the true flexion creases.

2 The transversal crease in marmosets and lemur is underdeveloped as compared to the typical Simian

Line - it looks more like a wavy proximal border of the interdigital pads.

${ }^{3}$ Vestigial Heart Line on some palm images of apes appears to be rather its "false" analogue (see text).

Table 5. Associations of finger movements in monkeys and apes. In the last column, fingers are united in linkage groups according to their common usage in cooperation

\begin{tabular}{|c|c|c|c|c|}
\hline Animals & $\begin{array}{l}\text { Typical } \\
\text { postures }\end{array}$ & Morphological basis & $\begin{array}{l}\text { Locomotory or } \\
\text { manipulatory usage }\end{array}$ & $\begin{array}{c}\text { Finger linkage } \\
\text { groups }\end{array}$ \\
\hline \multicolumn{5}{|c|}{ Equivalence of fingers } \\
\hline $\begin{array}{l}\text { Marmosets, e.g. } \\
\text { Callithrix, } \\
\text { Cebuella }\end{array}$ & & $\begin{array}{l}\text { Thumb is shifted distally and so aligned } \\
\text { with other fingers; it can be only somewhat } \\
\text { abducted but not opposed to them. }\end{array}$ & $\begin{array}{l}\text { Running over branches and } \\
\text { climbing vertical tree trunks. }\end{array}$ & $I-V$ \\
\hline \multicolumn{5}{|c|}{ Syndactyly } \\
\hline $\begin{array}{l}\text { Leontopithecus }^{2} \\
\text { and some } \\
\text { tamarins }\end{array}$ & & $\begin{array}{l}\text { Palm is elongated like the sole, the basal } \\
\text { phalanges of three middle fingers (II-IV) } \\
\text { are joined by a single sheath of skin. }\end{array}$ & $\begin{array}{l}\text { Running over branches and } \\
\text { climbing vertical tree trunks. }\end{array}$ & $\begin{array}{l}\text { I, } \\
\text { II-IV (joined), } \\
\text { V }\end{array}$ \\
\hline \multicolumn{5}{|c|}{ Hook grip } \\
\hline $\begin{array}{l}\text { Ateles }^{3}, \\
\text { Lagothrix, } \\
\text { Brachyteles, } \\
\text { Hylobates, } \\
\text { Pongo }\end{array}$ & & $\begin{array}{l}\text { The thumb is shortened, shifted proximally } \\
\text { or absent. }\end{array}$ & Brachiation. & $\begin{array}{l}\text { I (if present), } \\
\text { II-V }\end{array}$ \\
\hline
\end{tabular}




\begin{tabular}{|c|c|c|c|c|}
\hline \multicolumn{5}{|c|}{ Schizodactyly } \\
\hline $\begin{array}{l}\text { Alouatta, } \\
\text { Cacajao, } \\
\text { Pithecia } \\
\text { Lagothrix }\end{array}$ & 8 & $\begin{array}{l}\text { A wide gap is developed between fingers II } \\
\text { and III allowing their wide abduction from } \\
\text { each other. }\end{array}$ & $\begin{array}{l}\text { Walking and running along thick } \\
\text { and sloping branches. }\end{array}$ & $\begin{array}{l}I-I I, \\
I I I-V\end{array}$ \\
\hline \multicolumn{5}{|c|}{ Pseudo-opposable thumb } \\
\hline $\begin{array}{l}\text { Cebus, } \\
\text { Sapajus }^{5}\end{array}$ & & $\begin{array}{l}\text { The thumb is partially opposed to the } \\
\text { other fingers, but the trapezo-metacarpal } \\
\text { joint is not saddle-shaped and its mobility } \\
\text { is rather restricted. }\end{array}$ & $\begin{array}{l}\text { Climbing, walking and running } \\
\text { over thin branches. }\end{array}$ & $\begin{array}{l}\text { I, } \\
\text { II-V }\end{array}$ \\
\hline \multicolumn{5}{|c|}{ True opposition of the thumb } \\
\hline $\begin{array}{l}\text { Catarrhini, e.g. } \\
\text { Chlorocebus }^{6}\end{array}$ & & $\begin{array}{l}\text { The thumb is opposed to the other fingers } \\
\text { in the saddle-shaped trapezo-metacarpal } \\
\text { joint. }\end{array}$ & $\begin{array}{l}\text { Climbing, walking and running } \\
\text { over thin branches. }\end{array}$ & $\begin{array}{l}\mathrm{I}, \\
\mathrm{II}-\mathrm{V}\end{array}$ \\
\hline \multicolumn{5}{|c|}{ Pointing gesture } \\
\hline $\begin{array}{l}\text { Pan } \\
\text { Homo }\end{array}$ & & $\begin{array}{l}\text { The index finger can be extended, while } \\
\text { others are kept flexed in a fist. }\end{array}$ & $\begin{array}{l}\text { Usage of the straight index finger } \\
\text { alone for food extraction from } \\
\text { narrow holes, pressing buttons, } \\
\text { etc. }\end{array}$ & $\begin{array}{l}\text { I, } \\
\text { II, } \\
\text { III-V }\end{array}$ \\
\hline \multicolumn{5}{|c|}{$\begin{array}{l}1 \text { Cebuella pygmaea - photo by Robert Alan Shaw from https://s3.amazonaws.com/classconnection/151/flashcards/11772151/ } \\
\text { jpg/2935526-pygmy-marmoset-5-weeks-callithrix-cebuella-pygmaea-in-front-of-a-white-background-stock-photo- } \\
\text { 154E3FEE5103F2D47E6-thumb400.jpg. } \\
2 \text { Leontopithecus rosalia - photo by Sergei Chichagov from http://zoogalaktika.ru/assets/images/mammalia/primates/platyrrhini/ } \\
\text { leontopithecus-chrysomelas/leontopithecus-chrysomelas_02.jpg. } \\
{ }^{3} \text { Ateles belzebuth - photo by Tim Laman from http://ngm.nationalgeographic.com/2013/01/yasuni-national-park/img/13-white- } \\
\text { bellied-spider-monkey-670.jpg. } \\
4 \text { Pithecia pithecia - photo by John White from https://calphotos.berkeley.edu/imgs/512x768/0000_0000/1105/1256.jpeg. } \\
5 \text { Sapajus libidinosus - photo by Barth Wright from https://encrypted-tbn0.gstatic.com/images?q=tbn:ANd9GcSxHboKcwX-3Ybx0LJ- } \\
\text { jXEcSAp4YSU5jUifcw-HahQoT2TXjYO_w. } \\
6 \text { Chlorocebus sabaeus - photo by Atamari from https://upload.wikimedia.org/wikipedia/commons/thumb/d/d9/Chlorocebus_ } \\
\text { sabaeus_0048.jpg/1024px-Chlorocebus_sabaeus_0048.jpg. } \\
7 \text { Pan - photo from http://wallpapers-fenix.eu/full/141203/165157990.jpg. }\end{array}$} \\
\hline
\end{tabular}

mal set" for humans never occurs in non-human primates. Sets of palmar flexion creases differ among nonhuman primates (Table 4). As a common feature, we can point out that in all primates, the Life Line is present and the Head Line is not. The most complete sets of flexion creases were observed in chimpanzees and gorillas.

Typical prehensive postures of some of the New World monkeys, which we studied morphologically, are summarized in Table 5. As an example of Old World monkeys, we have included Chlorocebus sabaeus. It has a "universal" type of locomotion - it can utilize different motion techniques, both in trees and on the ground, and is not narrowly specialized in any of them. Now let us consider the palmar flexion creases line by line.
LIFE LINE

This line delimiting the thumb base is first to form in human embryogenesis and is always present in all the primates. The fact that it is present even in Ateles, which lacks the thumb itself (Table 6) (Viliamovskaya, 1955), implies its genetic, not functional, determination. Thus, this line belongs to the group of primary flexion creases in the strictest sense of this term, not only in humans.

The Life Line indicates the opposition of the thumb against other fingers. Thus, it corresponds to the presence of "linkage group I" against fingers II-V. The wider the arc of the Life Line is, the greater degree of thumb opposition we can expect. For instance, in gorillas this 
Table 6. Life line and thumb features in simians using different types of locomotion

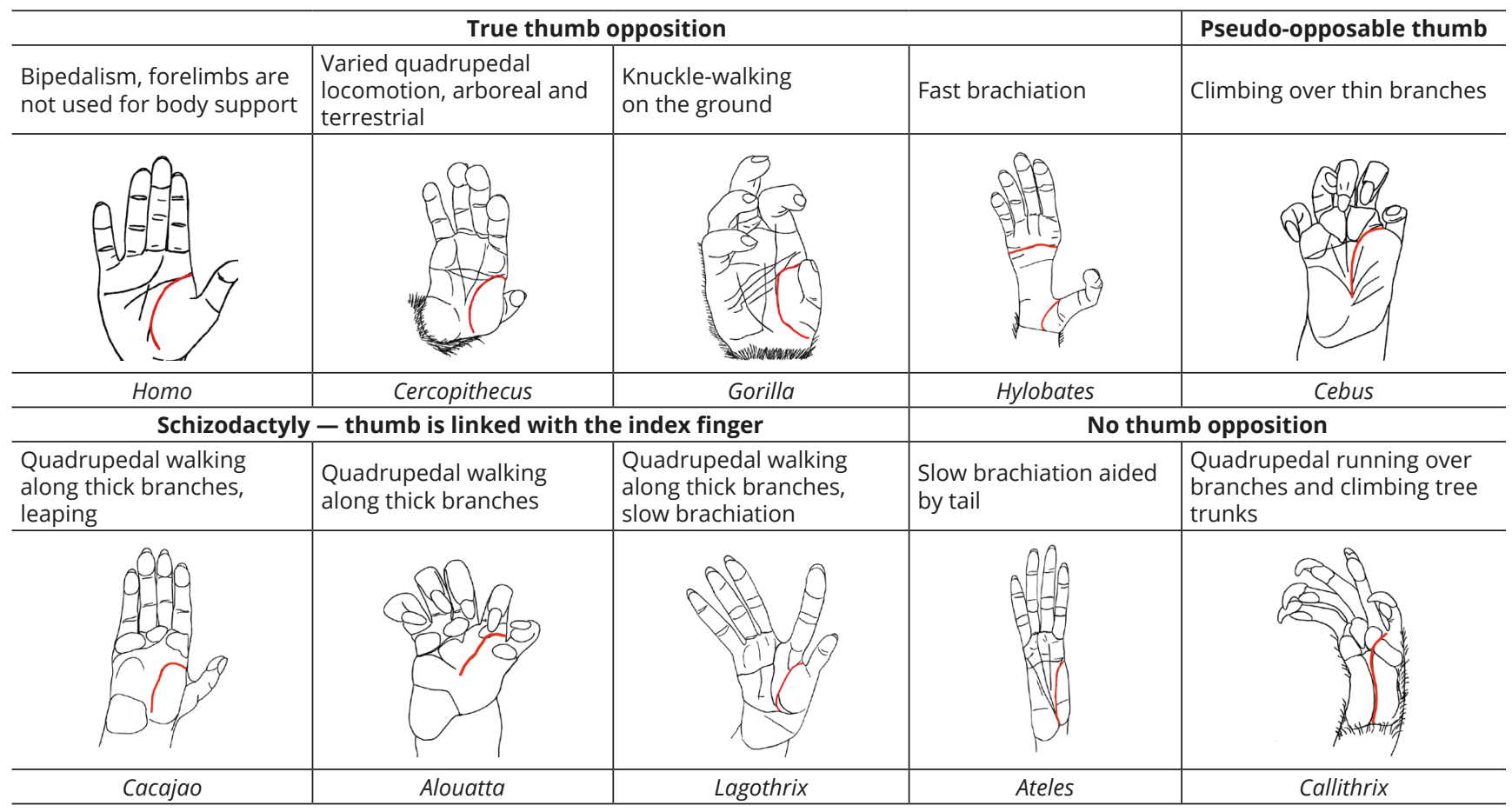

line departs from the thumb less than in humans, and the thumb is much shorter. The shortness makes it difficult to reach pad-to-pad opposition with the index finger when grasping small objects, so the pad-to-side grip is used instead - the pad of the thumb is pressed against preaxial side of bent index finger (Fig. 3). This involves more adduction of the thumb and less opposition than in the pad-to-pad grip.

Ateles and gibbons mainly use brachiation to move around. In gibbons the Life Line is short, but it appears to be sufficient for thumb opposition, as the thumb is "proximally seated". The proximal relocation is due to a shorter metacarpal I and a deeper interdigital notch III (it cuts the palm almost to the base of metacarpus) than in other primates. Ateles also has a narrow elongated hand adapted for brachiation. However, unlike in gibbons, its thumb did not undergo proximal relocation, but became so reduced that it does not even protrude from the palm. Ateles' Life Line reaches the preaxial edge of the palm only slightly proximally to the transverse Simian Line. Such a distal starting point of the Life Line may indicate an ancestral position of the thumb in spider monkeys before its reduction - as distal, as in all New World monkeys.

Members of families Cebidae and Atelidae have a Life Line that ends not at the base of the palm, like in other primates including humans, but slightly more distally. This is surprising when taking into account the fact that in capuchins thumb opposition is achieved not in the trapezo-metacarpal joint, employed by Old World monkeys, apes and humans, but in a more proximal ar- ticulation. The trapezo-metacarpal joint of capuchins has no pronounced saddle for bidirectional mobility (Aversi-Ferreira et al., 2014), and opposition of the thumb is performed proximal to the trapezoid, in the scapho-trapezoid joint (Danilova, 1979). That is why the capuchin's thumb is conventionally called "pseudo-opposable", to set it apart from the "true opposition" in the saddle-shaped trapezo-metacarpal joint of Catarrhini (Napier, 1961; Danilova, 1979).

In marmosets the thumb is considerably shifted distally - it is almost level with the other fingers and can be called "distally seated". The thumb pad undergoes the same shift - in marmosets it doesn't merge with the thenar. At the same time, the Life Line becomes almost longitudinal in its orientation, i.e. functionally it becomes another longitudinal flexion crease on par with the Fate Line. Marmosets almost do not oppose the thumb, but they can abduct it with a greater angular amplitude than other fingers. Altogether these features can be regarded as a sign of secondary simplification of the grasping function, because even Strepsirrhini have developed some opposition of the thumb (Napier, 1961).

\section{HEART LINE}

This line is second to form in human embryogenesis. Apart from humans, it is definitely found only in schizodactylous New World monkeys - Alouatta, Cacajao, Pithecia, Lagothrix. These monkeys typically walk quadrupedally along thick slanted or horizontal branches. In the schizodactylous prehensive pattern, fingers II and III 


\begin{tabular}{l|l|l|l|}
\hline \multicolumn{3}{c|}{ Schizodactyly } & \multirow{2}{*}{$\begin{array}{l}\text { Walking along thick horizontal } \\
\text { branches, slow brachiation }\end{array}$} \\
$\begin{array}{l}\text { Walking along thick horizontal } \\
\text { branches, leaping }\end{array}$ & $\begin{array}{l}\text { Walking along thick horizontal } \\
\text { branches }\end{array}$ \\
\hline Cacajao & Alouatta & Lagothrix &
\end{tabular}

are abducted from each other to form a wide gap, which allows the monkeys to grip the branch from both sides, positioning the palm almost along it (not across, as occurs with thumb opposition) and putting full weight on the base of the palm (Table 5).

The Heart Line in schizodactylous New World monkeys is more slanted than in humans - it runs diagonally, not transversally - and its end is located exactly at the notch between fingers II and III. In humans the Heart Line is found at the level of the metacarpophalangeal joints, usually looks like an arc turning from transverse orientation at the postaxial edge of the palm to slanting at the base of finger III, and ends either at the notch (which is not as deep as in the previous case) between fingers II and III, or on the respective interdigital pad (Viliamovskaya, 1955; Chauhan, 2011). Comparison with humans allows us to appreciate the significance of the slanted Heart Line in New World monkeys: being more longitudinal, it divides the palm into two subequal parts and facilitates their folding towards each other in the schizodactylous grip.

On gorilla palms (Table 7), there is a line that could be taken for a Heart Line if it didn't have a different topography. Heart Lines in humans and New World monkeys always pass proximally to the last two interdigital pads, but in gorillas it is found more distally. However, this line is not a product of fusion of Basal Rings either, because they are all in place. The line in question may be not the true Heart Line shifted distally, but rather its analogue, a secondary flexion crease playing the same role, i.e. facilitating the cooperation of fingers III and IV. Further studies of gorilla embryos are necessary to find out the exact nature of this flexion crease.

There is no doubt that the Heart Line of New World monkeys evolved independently from that of anthropoids. In gorillas it is most likely false, as was mentioned above. In humans it is always accompanied by the Head Line (see below), which suggests that both these lines are probably two halves of a single ancestral four-finger crease. Contrary to that, the Heart Line of the schizodactylous New World monkeys most likely represents the entire four-finger flexion crease of their ancestors, the end of which has shifted from the first interdigital notch (between fingers I and II) to the second (between fingers II and III). With this shift, the crease facilitated cooperative flexion of fingers III-V instead of II-V, while in humans the linkage group III-V was enhanced without any harm to that of fingers II-V.

\section{HEAD LINE}

This line is definitely found only in humans. It is third to form in human embryogenesis and begins on the preaxial side of the metacarpophalangeal joint II (Fig. 1), where it either merges with the Life Line or is parallel to it. From the first interdigital area it runs across the palm transversely or diagonally and terminates on the hypothenar but does not reach the postaxial edge of the palm, contrary to the four-finger Simian Line considered below. For the Head Line, we can suggest a new morphologic term which is more exact than previously used (see Table 3) - the subindex crease (plica flexoria transversa subindicis).

The Head Line never seems to be employed alone. Together with the Heart Line, it facilitates cooperative flexion of fingers II-V. In this partnership, the Head Line plays the role of the preaxial part of the four-finger crease, while the Heart Line acts as the postaxial one. The Heart Line alone would not facilitate four-finger flexion, while the single four-finger crease would not help to extend the index finger alone, holding fingers III-V flexed, to form the pointing gesture. The last can be regarded as a prehensive pattern (sensu Bishop, 1962) for extraction of small objects from narrow holes.

Danilova (1979) stated that primates rarely use this prehensive pattern. Only once did she observe a chimpanzee that used its index finger to extract a nut from a round hole in the floorboard. However, chimpanzees are well known to press keyboard buttons with the index finger, a fact which proves their ability to use the pointing gesture as a prehensive pattern for manipulation. One can suppose that the schizodactylous New World monkeys can perform the pointing gesture too, because they possess both necessary flexion creases. Howev- 
Table 8. Transversal creases in monkeys and apes using different types of locomotion

\begin{tabular}{c|l|l|l|l|l}
\hline Tree trunk climbing & Slow brachiation & Universal & Fast brachiation & Knuckle-walking & $\begin{array}{l}\text { Small object } \\
\text { manipulation }\end{array}$ \\
\hline Callithrix & Ateles & Cercopithecus & Hylobates & Gorilla \\
\hline
\end{tabular}

er, there is no factual evidence for this, and it is most likely that coexistence of the Heart Line and Life Line only serves them to vary the schizodactylous grip when walking along branches. Situations may occur when fingers III-V on one side of the branch are opposed not to fingers I and II on the other side, as in the canonical schizodactylous grip, but to finger I only, while finger II is placed over the branch and points forward along it, as if performing the pointing gesture in the direction of the monkey's movement.

It is interesting to note that in an experiment, tufted capuchins (Cebus apella) proved their ability to extract small food objects from narrow tubes with the index finger (Spinozzi et al., 2007). This could not be predicted from their flexion creases: they possess the Simian Line, indicative of the linkage group II-V, but not the Heart Line, which facilitates the pointing gesture. The absence of the Heart Line delimiting fingers II and III may be the reason for rather frequent conjoined usage of these fingers to extract objects from narrow tubes by capuchins in the experiments cited (Spinozzi et al., 2007).

\section{SIMIAN LINE}

Rarely observed in humans, if present this line is considered to be an atavism (see below) and is formed late in embryogenesis. The earliest case it has been found was at 15 weeks gestation, and the fetus had a normal karyotype (Sherer and Abramowicz, 1991).

In marmosets the transversal flexion crease is vestigial. Unlike in other primates, this crease braces the bases of all their fingers, including the thumb, which is very distally seated (Table 8). Therefore, the transversal flexion crease in marmosets aids the use of a linkage group $\mathrm{I}-\mathrm{V}$, not II-V as in other primates, and thus it should be named a five-finger flexion crease. There is a clear reason for such a total linkage. Marmosets typically climb vertical tree trunks, searching for food. There is no possibility to grasp the whole of the trunk; thus, there is no need for thumb opposition, and the thumb is shaped and used more similarly to the other four fingers. To hold on the vertical surface, marmosets spread their fingers wide and drive their claws (a unique feature among primates) into the bark by total finger flexion.

Furthermore, the transversal flexion crease of marmosets is intersected by several longitudinal creases (Fate Line, Life Line) which divide it into several fragments. It doesn't appear continuous and clear, but more like a broken line, bordering proximal edges of interdigital pads (including the thumb pad which remains separate from the thenar in marmosets). In some Callitrichids (such as the red-handed tamarin Saguinus midas, silvery marmoset Mico argentatus and others), the middle interdigital pads are so elongated proximo-distally that they completely destroy the entity of transversal line (Hill, 1957). This line also cannot be distinguished in Leontopithecus rosalia. If pronounced at all, the transversal flexion crease of marmosets is in fact just an outline of the proximal border of all four interdigital pads facilitating cooperative flexion of fingers I-V. The absence of any other considerable transversal wrinkles on the palm of marmosets makes it the only possible candidate for a homologue of transversal flexion creases of other primates.

In all other primates, with the exception of schizodactylous New World monkeys, the typical transversal flexion crease is present. It is the proper four-finger flexion crease, which cuts across the palm from one edge to another, bypassing only the thumb and thus bracing the linkage group II-V (Table 8). It is useful for power grip by these fingers together against the palm. In humans the four-finger flexion crease is a rare anomaly called the Simian Line. It occurs almost twice as frequently in archaic African pygmies and Melanesians as in other peoples (Geipel, 1961; see also review by Kimura, 1968). This fact supports the idea of homology of this abnormal four-finger Simian Line of humans and the normal four-finger flexion crease of non-human primates. Bali (1994) has listed a number of scientists who adhered to this homologation, beginning with Langdon-Down himself.

Viliamovskaya (1955) and Sharma and Sharma (2011) think that the Simian Line in humans is always formed as a fusion of a normal Head Line and Heart Line. In human evolution, a reverse process of fragmen- 
tation of the single ancestral four-finger crease may have taken place, its postaxial segment becoming the Heart Line, and its preaxial one - the Head Line. This hypothesis is apparently contradicted by the fact that in human embryogenesis the former appears before the latter, not at the same time. This contradiction could be resolved if it were shown that in non-human primates the fourfinger crease is formed beginning with its postaxial part too, but at the moment appropriate data is lacking.

Also, the aforementioned problem is still open as to the nature of the four-finger crease in Sydney and Suwon cases - is it a fusion of the Head Line and Heart Line or a reshaping of one or the other? Superficially, the Sydney case looks like a Simian Line combined with a Heart Line (Fig. 2A), while the Suwon case looks like a Simian Line combined with a Head Line (Fig. 2B). Variations of Suwon pattern (Sharma and Sharma, 2011) suggest that its "Head-like" crease is not the true Head Line but its analog, a secondary flexion crease branching from the Life Line. In the Sydney case its "Heart-like" crease looks more like the true Heart Line and, if so, its four-finger crease represents the result of postaxial elongation of Head Line alone. However, the aforementioned false Heart Line of gorillas suggests a similar possibility for the Sydney case. If the accessory lines in Sydney and Suwon cases are secondary, than the true Head Line and Heart Line are both merged into the four-finger crease, which then is the true Simian Line strictly homologous to that of other primates.

Several transversal four-finger lines, passing from one edge of the palm to another, can be found in hominids (Bali, 1994). It is hard to discern the exact nature of each one of these flexion creases based on photographic data only. It is possible that some of them are secondary flexion creases representing evolutionary innovations, and the others include primary homologues of the human Head Line and Heart Line, fused or already separate from each other. It would be interesting to trace their origin in embryogenesis, remembering that primary flexion creases are distinguished by appearance before onset of fetal hand movements, while secondary ones are formed later as a consequence of the hand movements.

\section{FATE LINE}

This line is longitudinal and is formed fourth in human embryogenesis, but in primate evolution it probably emerged before the transversal flexion creases. Based on its distribution among primate taxa (Table 4), only the Life Line is more ancient than this.

In most marmosets there are two Fate Lines (Table 9). They begin close together at the base of the palm or a bit more distally, and they descend along the midline of the palm between the central pads, diverging from each other to terminate at interdigital notches II-
III and IV-V. In Leontopithecus rosalia and several tamarins there is only one Fate Line. It runs straight along the midline towards the base of the third finger. Sometimes a second Fate Line can be found in these species. It branches towards the interdigital notch IV-V from the middle of the major Fate Line but is not as prominent.

Longitudinal flexion creases (Fate Lines and longitudinally shifted Life Line) facilitate trough-like folding of the palm. This allows some preaxial-to-postaxial opposition (thenar against hypothenar, first interdigital pad against the last, finger I against finger V), which helps to adjust palm concavity to substrate convexity when climbing a tree trunk and placing the hand along it, as marmosets do. It appears that longitudinal creases indicate a more pronounced adaptation for quadrupedal locomotion than for object manipulation. In marmosets, the flexion crease pattern and overall proportions of the palm are indeed similar to those of the sole. And in general, the flexion crease pattern of non-human primate palms is more similar to that of the soles than in humans (Viliamovskaya, 1955).

However, in some cases the pes-like manus represents a very peculiar manipulatory adaptation. In Leontopithecus rosalia, the palm is even more similar to the sole than in other marmosets - it is longer and thinner. Such hands are regarded as an obvious advantage when extracting insects from between tightly packed leafs of bromeliads (Rylands, 1989). In narrow crevices like this, scissor grips between sides of fingers are appropriate, and the ability for trough-like folding of the palm, facilitated by the longitudinal Fate Line, is also useful. We hypothesize that Leontopithecus rosalia can perform a peculiar "forceps grip" with its trough-folded hand, with three middle fingers acting as one branch and fingers $\mathrm{I}+\mathrm{V}$ as another. This unusual grip has never been observed but is strongly suggested by syndactyly - in Leontopithecus rosalia the bases of the middle three fingers are held together by a common skin sheath (fingers III-IV are connected all the way along their proximal phalanges, II-III - a bit less). Syndactyly of fingers IIIII is also found in some species of tamarins, e.g., Saguinus mystax, but their connection doesn't go as distally as in Leontopithecus rosalia (Hill, 1957).

Apart from marmosets and tamarins, New World monkeys do not have clear longitudinal palmar creases. They can be present or absent in Old World monkeys, and they are found in prosimians. In these groups there are two Fate Lines like in marmosets. This allows us to state that in primate evolution the presence of two longitudinal creases was the ancestral condition, and that later on they were lost in favor of transversal flexion creases as a mean to enhance power grip.

The Fate Line in marmosets, based on its morphological prominence, looks like a primary flexion crease. Contrary to that, in humans the Fate Line is regarded 
Table 9. Diversity of Fate Lines in marmosets

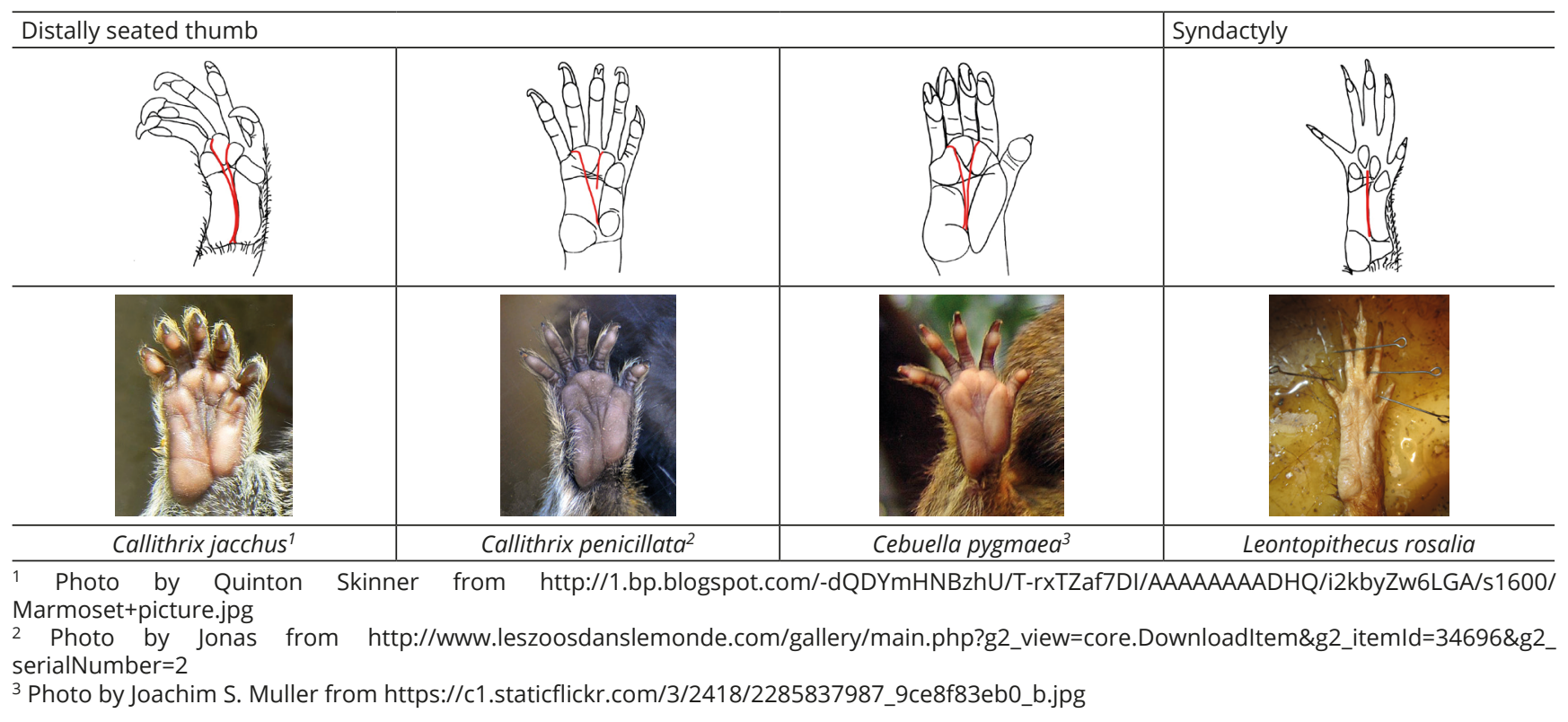

as a secondary flexion crease because it forms during embryogenesis long after the onset of hand movements (Bali, 1994). It also cannot be assigned to the primary flexion crease category, because it is irregular in form, placement and depth and often disappears in adults. However, other secondary flexion creases form even later in life. So either the human Fate Line is a secondary flexion crease which tends to become primary, or the other way round - it is a remnant of the ancestral longitudinal flexion crease diminishing from primary to secondary condition. The latter seems more plausible.

\section{BASAL RINGS}

In most primates, including humans, short flexion creases exist at the base of each finger where it protrudes from the palm. Together, the Basal Rings represent the distal boundary of the palm, but they can be employed separately in flexion of respective individual fingers, thus not indicating any linkage groups. However, Leontopithecus rosalia, due to partial fusion of the three middle fingers (syndactyly) can only flex them all together, so its fingers II-IV have a single Basal Ring instead of three separate ones. This flexion crease is not very prominent, probably because finger fusion restricts degree of flexion.

\section{TRAVEL LINE}

This line divides the hypothenar in two. In adult humans it is usually absent, but can be traced in an embryo. On the contrary, in most non-human primates it is well developed. Its development correlates with development of the pisiform bone. It is especially large and elongated in those primates who mainly use quadrupedal locomo- tion. It serves as a "heel" and forms postaxial flange of a passage for flexor tendons from the forearm to the manus. The Travel Line passes distally to the pisiform bone across the hypothenar, separating it into a proximal part, playing the role of "pisiform shoe", and a distal part.

\section{BRACELETS}

Flexion creases of the wrist (usually several of them) border the palm proximally in all primates with no exceptions, because skin always wrinkles here, facilitating flexion in the radiocarpal joint.

\section{Discussion}

We hypothesize that palmar flexion creases should correspond to linkage groups. For illustrative comparison of flexion creases with linkage groups, see Table 10 . Finger movements in humans are more diverse, which is evident in flexion creases of the palm. However, enhanced ability of some people to move their fingers both individually and in different combinations (for example, while playing a musical instrument) has no impact on the primary flexion creases. This could be explained by the fact that those motions are not typical and their morphological basis is not yet established via natural selection. Professional activities can only influence the formation of secondary flexion creases. In humans those creases usually differ between left and right palms. In some cases non-human primates also use non-typical finger motions, which have no impact on the set of primary flexion creases. For example, a prehensive pattern such as the pointing gesture is used but rarely by chimpanzees (Danilova, 1979) and capuchin monkeys (Spi- 
Table 10. Typical examples of palmar flexion creases and respective finger linkage groups represented by lifetime photos (Lemur, Ateles, Homo) and alcohol specimens (all the rest), and by respective line drawings

\begin{tabular}{l}
$\begin{array}{l}\text { Life Line } \\
\text { for thumb opposition Fate Lines } \\
\text { bordering interdigital palm pads }\end{array}$ \\
\hline for trough-folding of the palm
\end{tabular}

${ }_{1}$ Photo of Lemur catta by Alex Dunkel from https://vignette.wikia.nocookie.net/lemurandbushbaby/images/1/13/800px-Lemur_catta_hand_01. jpg; the other photos are original.

nozzi et al., 2007). This logic also works the other way round: absence of a specific flexion crease can point to rarity of respective finger motions.

New World monkeys, as well as other primates, employ a very diverse range of hand postures in locomotion and a wide repertoire of object grasping methods. Our research allowed us to describe prehensive patterns and grips in terms of linkage groups of fingers (Table 5), and to find associations between the linkage types and the presence of particular palmar flexion creases (Table 10). These associations are well expressed in line combinations.

\section{EXISTING LINE COMBINATIONS}

Having discussed each line separately, we should review line combinations as a complete system. Shyamacharan and Dayabati (2008) recognize three types of combinations in humans: quartet (simultaneous presence of three primary flexion creases and the Fate Line), triplet (three primary flexion creases) and simian type (two flexion creases). In both men and women, the quartet is more frequently observed on the left hand, the triplet on the right hand. On the leading hand (the right one, as most people are right-handed) there are fewer lines because the secondary Fate Line can disappear with age, when overall palm relief evens out due to everyday labor.

The situation grows more complex when nonhuman primates are taken into account. In theory, 128 combinations are possible if one counts presence or absence of one or two longitudinal creases (Fate Lines) and all the five known transversal creases (the Heart Line, Head Line, four-finger Simian Line with or without its doublet, and five-finger crease). To simplify our analysis, we will discard their quantitative variables (exact positions of start and end points, length, deviation from longitudinal or transversal direction, etc.) and concentrate only on presence or absence of the lines in question. Following Shyamacharan and Dayabati (2008), we will not include in our combinatorics the Life Line, Rings and Bracelets because they are always present, and the Travel Line because it is, on the contrary, too irregular. In Table 11 all combinations of transversal and longitudinal lines really observed in primates are shown. Their number is eleven, much less than the theoretically possible 128 - a deficiency which supports the idea of their adaptive significance.

The Simian four-finger flexion crease alone (combination F in Table 11) is observed in Old World monkeys and gibbons, some New World monkeys (for example Ateles) and, as a rare anomaly, in humans; it can be regarded as the most general simian condition. Two fourfinger flexion creases (Simian Line with its doublet) (G in Table 11) are characteristic for hominids. The combination of Heart and Head Lines (H, I in Table 11) as well as rare combinations of their analogs with the Simian Line (J, K in Table 11) are characteristic only for humans.

The combination of a Simian four-finger flexion crease and two Fate Lines (C in Table 11) can be regarded as basal for primates as it is shared by Strepsirrhini, some Platyrrhini and some Catarrhini. All other real combinations (four out of eleven) are found in New World 
Table 11. Combinations of transversal and longitudinal flexion creases found in various primates. For comparability all are plotted on the palm outline of Cercopithecus. Positions of particular combinations in the table do not represent evolutionary sequences but are chosen so as to facilitate visual comparisons. Major diversity of New World monkeys is represented in the top row, the bottom row represents diversity of apes and humans (including norm and variations), and the column C-F-G logically bridges the two rows

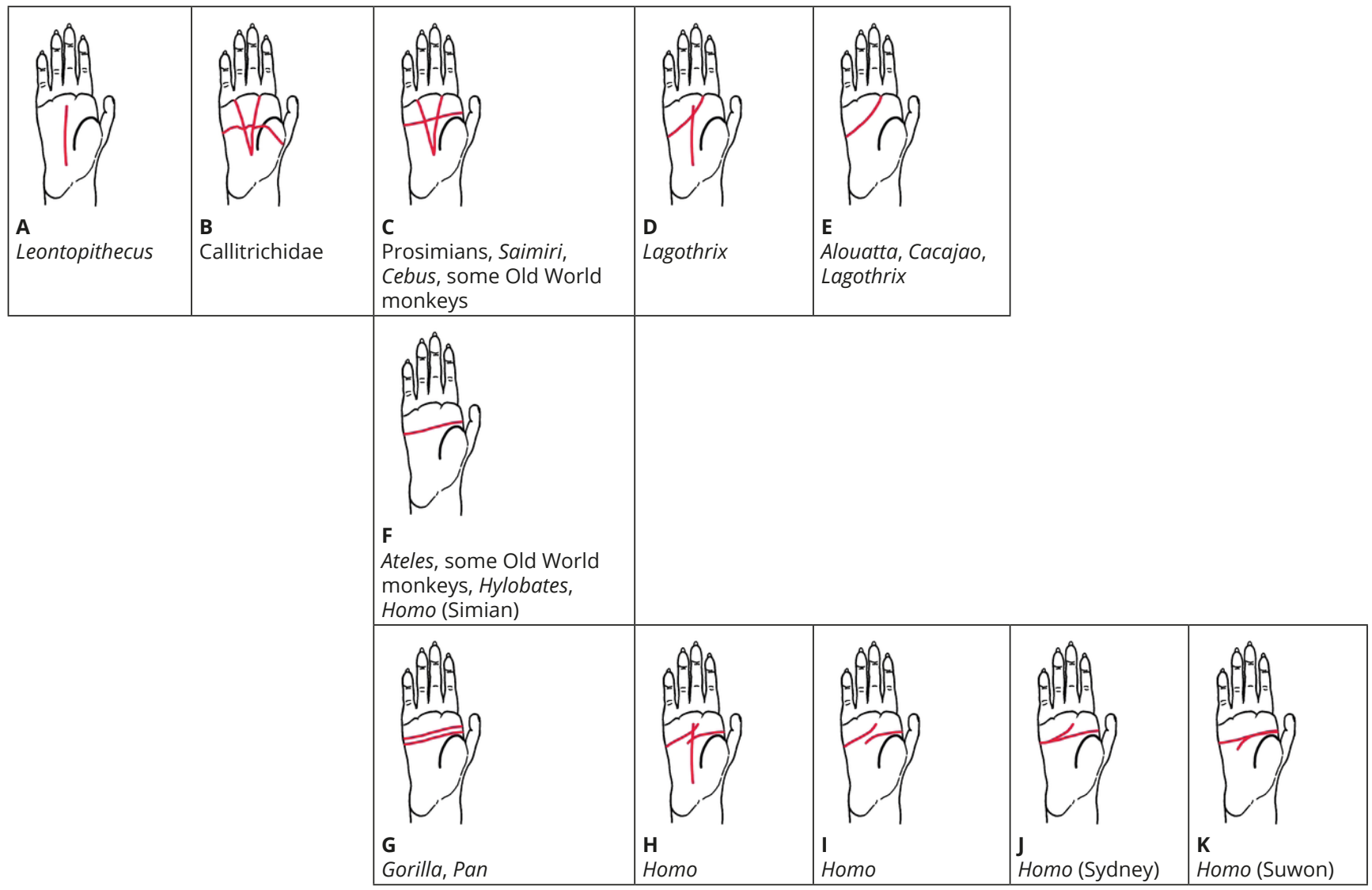

monkeys only (A, B, D, E in Table 11). Contrary to that, in Old World monkeys only types $\mathrm{C}$ and $\mathrm{F}$ are observed, since they do not have such traits as schizodactyly with the Heart Line, like in Cacajao, or the five-finger flexion crease, like in marmosets. So, among Catarrhini, the diversity of creases is accounted for by hominids and humans with their individual variations.

\section{Conclusion}

Palmar flexion creases can serve as a good reference point when describing grip variations, and in general they correlate with finger linkage groups. Since flexion creases are adaptive in their nature, they evolve according to changes of grip type. In general, object grasping, finger linkage and flexion crease sets are more variable in New World monkeys than in other primates. Summarizing, we conclude that there are two peaks in crease diversity: the basal diversity of Platyrrhini opposed by the crown diversity of hominids and humans. Especially complicated was the evolution of transversal creases (see Fig. 4 for our proposed evolutionary scenario).
In the most primitive New World monkeys (marmosets, owl monkeys, squirrel monkeys) and in many prosimians, palm pads (even central ones) and longitudinal flexion creases (Fate Lines) are well developed, and their palms look similar to soles. The transversal flexion crease in marmosets and prosimians is poorly pronounced and looks like a thin broken wrinkle bordering the proximal edges of interdigital pads. The specific trait of marmosets is that their thumb is seated distally to the transversal flexion crease, which makes the crease itself five-finger (Fig. 4B2), as opposed to the four-finger Simian Line found in prosimians and most other monkeys (Fig. 4A). The thumb is shifted distally in marmosets in order to form one row with the other fingers, and all five fingers are armed with claws to climb thick tree trunks, unlike in any other primates. This adaptation is associated with restriction of both abilities which we regard as basal for primates as a whole - namely, the ability for thumb opposition and the ability for power grip by the other four fingers.

In more advanced forms of New World monkeys, as new types of grip emerge, the transversal flexion crease 


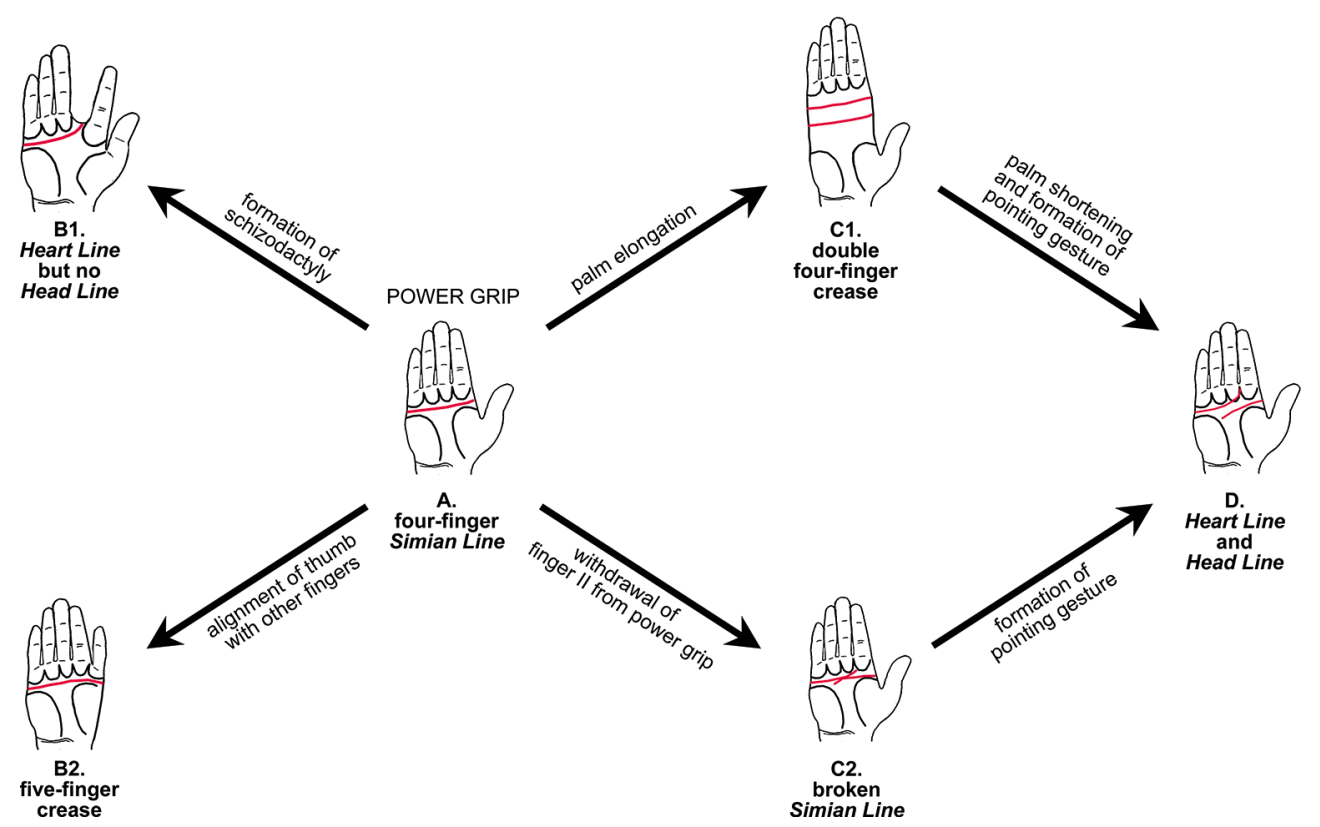

Fig. 4. Diagram of proposed evolutionary transformations of transversal flexion creases on primate palm. Longitudinal creases are not shown. All morphotypes are plotted on the outline of a human hand, slightly reshaped as necessary. A — basic primate morphotype. B - two morphotypes unique to New World monkeys (B1 - howler and uakari, B2 - marmosets). Evolutionary pathway from the basic morphotype (A) to Homo (D) goes either through the ape morphotype (C1) or through hypothetical but more straightforward stage (C2)

becomes more prominent and takes one or the other position on the palm facilitating the use of respective finger linkage groups. The transversal four-finger flexion crease, known as the Simian Line and shared with lemurs and Old World monkeys, is retained in those New World monkeys who use brachiation or climb over thin branches (Fig. 4A). A slanted Heart Line and the corresponding finger linkage group III-V are specific to New World monkeys relying upon schizodactylous grip when walking along thick sub-horizontal branches (Fig. 4B1).

In humans the Heart Line was formed in a different way than in schizodactylous Platyrrhini. The fourfinger Simian Line did not turn into a three-finger Heart Line, but broke into two - the Heart Line and Head Line (Fig. 4D). There are two possible ways for this breakage (Fig. 4C1, C2). Together, the Heart Line and Head Line retain the role of the Simian Line, facilitating flexion of fingers II-V all together. The Heart Line alone facilitates flexion of fingers III-V, so that the index finger becomes unlinked from the other three. This helps employment of the pointing gesture as a new and very important human prehensive pattern. The other important enhancement of human prehensive abilities was associated with progressive development of pad-to-pad thumb opposition facilitated by the Life Line. This line is the most constant palmar crease in primates, which means that thumb opposition in some primitive form was primates' initial feature since the times when the pads were reduced in favor of creases. This conclusion is rather close to that of Boyer et al. (2013), who, based on hand skele- ton morphometrics in both extant and extinct primates, proposed that strong divergence of the thumb from the other digits may be an original feature of primates.

\section{Acknowledgements}

We are very indebted to Dr. Aleksandra A. Panyutina for her extensive technical help and encouragement.

\section{References}

Aversi-Ferreira, R.A. G. M. F., Maior, R.S., Aziz, A., Ziermann, J. M., Nishijo, H., Tomaz, C., et al. 2014. Anatomical Analysis of Thumb Opponency Movement in the Capuchin Monkey (Sapajus Sp). PLoS ONE 9(2):e87288. https://doi.org/10.1371/journal.pone.0087288

Asano, H. 1985. Hands: The Complete Book of Palmistry. Tokyo, Japan Publications.

Aziz, M. A., and Dunlap, S. S. 1986. The human extensor digitorum profundus muscle with comments on the evolution of the primate hand. Primates 27:293-319. https:// doi.org/10.1007/BF02382073

Bali, R. S. 1994. Anthropology of Crease Morphogenesis: A Scientific Analysis. New Delhi, Concept Publishing Company.

Bishop, A. 1962. Control of the hand in lower primates. Annals of the New York Academy of Sciences 102:316-337. https:// doi.org/10.1111/j.1749-6632.1962.tb13649.x

Boyer, D. M., Yapuncich, G. S., Chester, S. G. B., Bloch, J. I., and Godinot, M. 2013. Hands of early primates. American Journal of Physical Anthropology 152:33-78. https://doi. org/10.1002/ajpa.22392

Chauhan, P., Kalra, S., Jain, S. K., Munjal, S., and Anurag, A. 2011. Relationship between palmar skin creases and osseous anatomy - a radiological study identification. Journal of Morphological Science 28:184-188.

Danilova, E. I. 1979. Evolution of the Hand. Kiev, Vyshaya Shkola (in Russian). 
Fragaszy, D. M., and Crast, J. 2016. Functions of the hand in primates. In Kivell, T. L., Lemelin, P., Richmond, B. G., and Schmitt, D. (eds.), The Evolution of the Primate Hand (pp. 313-344). New York, Springer. https://doi. org/10.1007/978-1-4939-3646-5_12

Geipel, G. 1961. Die Vierfingerfurche bei afrikanischen und melanesischen Pygmäen im Vergleich mit Negern und Deutschen. Zeitschrift fürMorphologie und Anthropologie 51:339-345.

Gyenis, G., and Hera, G. 1971. Investigation of the hand creases in the random sample of subjects in Baranya Province of South Hungary. Anthropologiai Kozlemenyek (Budapest) 15:29-47.

Hill, W. C. O. 1957. Primates - comparative anatomy and taxonomy. III. Pithecoidea, Platyrrhini (families Hapalidae and Callimiconidae). Edinburgh, University Press.

Humphrey, T. 1964. Some correlations between the appearance of human fetal reflexes and the development of the nervous system. Progress in Brain Research 4:93-135. https://doi.org/10.1016/S0079-6123(08)61273-X

Jeanty, P., Clavelli, W. A., and Romaris, S. S. 2011. Ultrasound detection of chromosomal anomalies. In Fleischer, A. C., Toy, E. C., Lee, W. et al. (Eds.), Sonography in Obstetrics and Gynecology: Principles and Practice, 7th Edition. New York, McGraw-Hill Education.

Kachlik, D., Musil, V., and Baca, V. 2015. Terminologia Anatomica after 17 years: Inconsistencies, mistakes and new proposals. Annals of Anatomy 201:8-16. https://doi org/10.1016/j.aanat.2015.04.006

Kimura, K. 1968. A Study of Palmar Crease in Ainus. Journal of the Anthropological Society of Nippon 76:60-74. https:// doi.org/10.1537/ase1911.76.60

Kimura, S. 1991. Embryologic development of flexion creases. Birth Defects: Original Article Series 27:113-129.

Kimura, S., and Kitagawa, T. 1986. Embryological development of human palmar, plantar, and digital flexion creases. The Anatomical Record 216:191-197. https://doi. org/10.1002/ar.1092160211

Kimura, S., Schaumann, B. A., and Shiota, K. 2002. Comparative investigations of human and rat dermatoglyphics: palmar, plantar and digital pads and flexion creases. Anatomical Science International 77:34-46. https://doi. org/10.1046/j.0022-7722.2002.00002.x

Lacroix, B., Wolff-Quenot, M. J., and Haffen, K. 1984. Early human hand. Early Human Development 9:127-136.

Martin, R. 1928. Lehrbuch der Anthropologie in systematischer Darstellung mit besonderer Berücksichtigung der anthropologischen Methoden für Studieren, Ärtze und Forschungsreisende. Band 3. Jena, Fischer.

Midlo, C., and Cummins, H. 1942. Palmar and plantar dermatoglyphics in primates. American Anatomical Memoirs 20:1-198

Napier, J. R. 1956. The prehensile movements of the human hand. Bone and Joint Journal 38:902-913.

Napier, J.R. 1960. Studies of the hands of living primates. Journal of Zoology 134:647-657. https://doi. org/10.1111/j.1469-7998.1960.tb05606.x
Napier, J. R. 1961. Prehensility and opposability in the hands of primates. Symposia of the Zoological Society of London $5: 115-132$

Novikova, M. A., and Panyutina, A. A. 2017. Structural diversity of extensor digitorum profundus muscle complex in Platyrrhini. Folia Primatologica 88:274-292. https://doi. org/10.1159/000478524

Park, J. S., Shin, D. S., Jung, W., and Chung, M. S. 2010. Improved analysis of palm creases. Anatomy and Cell Biology 43:169-177. https://doi.org/10.5115/acb.2010.43.2.169

Popich, G. A., and Smith, D. W. 1970. The genesis and significance of digital and palmar band creases: preliminary report. The Journal of Pediatrics 77:1017-1023. https:// doi.org/10.1016/S0022-3476(70)80086-5

Rylands, A. B. 1989. Sympatric Brazilian callitrichids: the Black Tufted-Ear Marmoset, Callithrix kuhli, and the Golden-Headed Lion Tamarin, Leontopithecus chrysomelas. Journal of Human Evolution 18:679-695. https://doi. org/10.1016/0047-2484(89)90100-0

Sharma, D. K., and Sharma, V. 2011. Prevalences of Simian, Sydney and Suwon creases and their association with each other, body sides, handedness, sex and anomalies/ diseases/syndromes in a population of Central India. International Journal of Morphology 29:1069-1075.

Sherer, D. M., and Abramowicz, J.S. 1991. Prenatal sonographic detection of Simian crease at 15 weeks gestation. Journal of Ultrasound in Medicine 10:298-299. https://doi.org/10.7863/jum.1991.10.6.298

Shyamacharan, S. T., and Dayabati, D. N. 2008. Palmar crease morphology: an approach. International Journal of Anthropology 23:51-59.

Spinozzi, G., Lagana, T., and Truppa, V. 2007. Hand use by tufted capuchins (Cebus apella) to extract a small food item from a tube: digit movements, hand preference, and performance. American Journal of Primatology 69:336-352. https://doi.org/10.1002/ajp.20352

Stevens, C. A., Carey, J. C., Shah, M., and Bagley, G.P. 1988. Development of human palmar and digital flexion creases. Journal of Pediatrics 113:128-132. https://doi. org/10.1016/S0022-3476(88)80546-8

Swindler, D. R., Jenkins, T. W., and Weiss, A. W.Jr. 1968. Fetal growth and development. In Malinow, M. R. (Ed.), Biology of the Howler Monkey (Alouatta caraya). Bibliotheca Primatologica, 7 (pp. 28-47). New York, Karger.

Tegako, L. I. 2008. Science chiromancy. Moscow, Eksmo. (in Russian)

Viliamovskaya, M. I. 1955. Flexion lines of human hand and foot in their development, age-related changes, and comparison with primates. (Unpublished doctoral dissertation). Leningrad. (in Russian)

Würth, A. 1937. Die Entstehung der Beugefurchen der menschlichen Hohlhand. Zeitschrift für Morphologie und Anthropologie 36:187-214.

Zvyagintseva, T.D. 1940. Papillary pattern of hand and foot in Papio and Macacus. Collection of scientific works of of student of Moscow State University 13:19-37. (in Russian) 


\title{
USED INTERNET RESOURCES
}

\author{
STREPSIRRHINI \\ Lemuridae \\ Lemur catta
}

https://vignette.wikia.nocookie.net/lemurandbushbaby/images/1/13/800px-Lemur_catta_hand_01.jpg

https://i.pinimg.com/originals/b4/d0/9b/b4d09b40100610a842e64e19b763527d.jpg

http://zagadkizemli.ru/uploads/posts/2013-05/1369156682_lemur-udivitelinoe-sozdanie-prirody.jpg

https://www.flickr.com/photos/37669825@N04/6103895277

\section{Loridae}

Nycticebus sp.

http://www.alltheworldsprimates.org/images/Lorisidae/Nycticebus\%20Unidentified\%20full\%20\%20hand\%20Cincinnati\%20 Zoo1996nbr.jpg

\section{Perodicticus potto}

http://www.alltheworldsprimates.org/images/Lorisidae/Perodicticus\%20potto\%20unid\%20foot\%20close\%20Boston\%20 zoo\%2092\%20NBR.879.jpg

\section{PLATYRRHINI}

\section{Cebidae}

Callithrix jacchus

http://1.bp.blogspot.com/-dQDYmHNBzhU/T-rxTZaf7DI/AAAAAAAADHQ/i2kbyZw6LGA/s1600/Marmoset+picture.jpg https://img.washingtonpost.com/wp-apps/imrs.php?src=https://img.washingtonpost.com/news/speaking-of-science/wpcontent/uploads/sites/36/2014/12/PHO-05Dec14-22565-785x1024.jpg\&w=1484

http://pin.primate.wisc.edu/callicam//callisnap.jpg

http://4.bp.blogspot.com/-pcMDaVmKfx0/UgB05YpiuWI/AAAAAAAAGsA/yrjUD4gD0Sg/s1600/

Monkey+Park+Common+Marmoset.jpg

\section{Callithrix penicillata}

http://www.leszoosdanslemonde.com/gallery/main.php?g2_view=core.Downloadltem\&g2_itemld=34696\&g2_serialNumber $=2$

\section{Cebuella pygmaea}

http://zipcodezoo.com/images/7/78/Callithrix_pygmaea_12.jpg

https://c1.staticflickr.com/3/2418/2285837987_9ce8f83eb0_b.jpg

https://farm2.static.flickr.com/1163/1418781402_41162b85ff_m.jpg

https://img-s-msn-com.akamaized.net/tenant/amp/entityid/BBqAVDH.img?h=1080\&w=1920\&m=6\&q=60\&o=f\&l=f\&x=1188 $\& y=888$

https://s3.amazonaws.com/classconnection/151/flashcards/11772151/jpg/2935526-pygmy-marmoset-5-weeks-callithrixcebuella-pygmaea-in-front-of-a-white-background-stock-photo-154E3FEE5103F2D47E6-thumb400.jpg

\section{Saguinus oedipus}

http://prokazan.ru/userfiles/old/newsinnerpic/edipov_tamarin.jpg

http://prokazan.ru/userfiles/old/newsinnerpic/edipov_tamarindd.jpg

Saguinus imperator

https://img-fotki.yandex.ru/get/6844/133599346.178/0_10082a_bd7caa79_X5L.jpg

Leontopithecus rosalia

https://static.ngs.ru/news/preview/d605a8426cea96c15cb15b5bb36a267c1291f094_900.jpg

http://zoogalaktika.ru/assets/images/mammalia/primates/platyrrhini/leontopithecus-chrysomelas/leontopithecus-chrysomelas_02.jpg 


\section{Cebus capucinus}

https://www.sciencedaily.com/images/2009/11/091104101553_1_900x600.jpg

Sapajus libidinosus

https://encrypted-tbn0.gstatic.com/images?q=tbn:ANd9GcSxHboKcwX-3YbxOLJ-jXEcSAp4YSU5jUifcw-HJahQoT2TXjYO_w

Saimiri sciureus

https://d2gg9evh47fn9z.cloudfront.net/800px_COLOURBOX6825890.jpg

https://pp.userapi.com/c308130/v308130463/7d0a/H_Sk_IsbV5k.jpg

https://s-media-cache-ak0.pinimg.com/originals/20/18/26/201826f66629835431422cdf33672e21.jpg

http://2.bp.blogspot.com/-0-Jip-Y7QhA/TfxGj-knegl/AAAAAAAAB3w/M1 kKdzZcYPI/s1600/2243401439

\section{Pitheciidae}

Cacajao calvus

http://www.arco-images.de/golduakari-golduakaris-roter-uakari-rote-uakaris-bilder-fotos/919928.jpg

Pithecia pithecia

https://calphotos.berkeley.edu/imgs/512x768/0000_0000/1105/1256.jpeg

\section{Atelidae}

Alouatta caraya

http://i.imgur.com/Zgq1xPt.png

Ateles belzebuth

http://ngm.nationalgeographic.com/2013/01/yasuni-national-park/img/13-white-bellied-spider-monkey-670.jpg

Ateles geoffroyi

https://upload.wikimedia.org/wikipedia/commons/d/de/Geoffroy_Spider_Monkey_Hand_1.jpg

Ateles sp.

https://media-cdn.tripadvisor.com/media/photo-s/05/3f/6d/59/el-nispero-zoo-and-botanical.jpg

Brachyteles arachnoides

https://upload.wikimedia.org/wikipedia/commons/2/28/Brachyteles_arachnoides_sorocaba_hand.JPG

Lagothrix lagotricha

http://cdn1.arkive.org/media/3A/3A615EF4-A7BD-4484-9977-34F92A89B212/Presentation.Large/Close-up-of-common-woolly-monkey-hand.jpg

\section{CATARRHINI}

\section{Cercopithecidae}

Chlorocebus sabaeus

http://c7.alamy.com/comp/CRC1HY/green-monkey-or-callithrix-monkey-chlorocebus-sabaeus-CRC1HY.jpg https://upload.wikimedia.org/wikipedia/commons/thumb/d/d9/Chlorocebus_sabaeus_0048.jpg/1024px-Chlorocebus_sabaeus_0048.jpg

\section{Cercopithecus neglectus}

https://c1.staticflickr.com/3/2770/4182171995_5c40ae191a_b.jpg 


\section{Macaca mulatta}

https://static.panoramio.com.storage.googleapis.com/photos/large/69126825.jpg

Macaca fuscata

http://www.thewildlifephotographer.com/wp-content/uploads/galleries/post-83/SnowMonkeyHand.jpg

http://c7.alamy.com/comp/ATFKRN/male-snow-monkey-holding-up-human-like-hand-snow-whilst-bathing-hot-ATFKRN.jpg

Colobus sp.

https://c1.staticflickr.com/5/4111/5608723126_ea13ae6c40_b.jpg

\section{Hylobatidae}

Hylobates lar

https://53744bf91d44b81762e0-fbbc959d4e21 c00b07dbe9c75f9c0b63.ssl.cf3.rackcdn.com/media/BE/BE94C463-88E2-4E4FB7D3-E9725E405C1E/Presentation.Large/Close-up-of-the-hand-of-a-white-handed-gibbon.jpg

https://img00.deviantart.net/ee6f/i/2013/201/d/e/gibbon_hand_by_yunaheileen-d6ec8ee.jpg

Hylobates pileatus

http://c7.alamy.com/comp/BHT6R9/the-hand-of-an-arboreal-crested-black-gibbon-reaching-through-the-BHT6R9.jpg

\section{Hominidae}

Pan troglodytes

https://i.pinimg.com/originals/8b/6f/84/8b6f849b6cd996ee33a23802625c88f6.jpg

Pan paniscus

https://cdn.zmescience.com/wp-content/uploads/2014/03/Close-up-of-bonobo-hand.jpg

http://www.vanessawoods.net/img/img_bonobo_1.jpg

Pan sp.

https://1.bp.blogspot.com/-S6uEbfJ1 phs/VdoxgaGAJcl/AAAAAAAAA34/oGyjfaZF9ps/s1600/ape\%2Bhand.jpg

http://media.gettyimages.com/photos/chimpanzee-hands-picture-id141249960

http://wallpapers-fenix.eu/full/141203/165157990.jpg

Gorilla sp.

https://encrypted-tbn0.gstatic.com/images?q=tbn:ANd9GcR75DBmgYXSKPPPm7U_R2nj1EShfcuKdLKtqzvdNgLiNNEaxbHY https://cdn.zmescience.com/wp-content/uploads/2014/03/gorilla-hand-lines.jpg

http://cdn.bolshoyvopros.ru/files/users/images/8f/ba/8fba9efb1d1738a26af3a9912499d495.jpg

\section{Pongo pygmaeus}

http://www.planetware.com/i/photo/orangutan-hand-borneo-mal226.jpg

https://media.buzzle.com/media/images-en/gallery/mammals/animal-cruelty/1200-118171533-animal-abuse.jpg

https://cdn.zmescience.com/wp-content/uploads/2014/03/lvBTT.jpg

http://c7.alamy.com/comp/C4DFAP/baby-orangutan-hand-clutching-a-wire-cage-C4DFAP.jpg 